\title{
ANTIMICROBIAL RESISTANCE OF ENTEROCOCCUS FAECIUM ISOLATED FROM THE URINARY SYSTEM OF DOGS
}

\author{
Sukru Kirkan ${ }^{1}$, Ugur Parin ${ }^{1}$, Gamze Balat ${ }^{2}$ \\ ${ }^{1}$ Department of Microbiology, Faculty of Veterinary Medicine, \\ Aydin Adnan Menderes University, Aydin, Turkey \\ ${ }^{2}$ Department of Microbiology, Health Sciences Institute, \\ Aydin Adnan Menderes University, Aydin, Turkey
}

Received 16 February 2018; Received in revised form 6 June 2018; Accepted 11 July 2018

\begin{abstract}
The purpose of the present study was to determine the antimicrobial susceptibility of vancomycin-resistant and Enterococcus faecium strains isolated from urine samples of dogs. A total of 22 Enterococcus sp. samples were isolated and identified from 100 urine samples collected by cystocentesis from dogs of both sexes. The identification with species specific primers for multiplex PCR revealed that all 22 isolates (100\%) belonged to E. faecium. Vancomycin resistance was found in $10(45 \%)$ samples of E. faecium strains with PCR study by vanA and vanB primers.
\end{abstract}

Key words: enterococci, E. faecium, vancomycin, vanA, vanB

\section{INTRODUCTION}

Enterococci, which can cause serious health problems in humans and animals, are opportunistic pathogenic microorganisms. Regarding pet animals, there are reports about infection caused by enterococci which were isolated from certain cases of urinary tract infections, periodontitis, osteomyelitis, gastroenteritis, peritonitis, and endocarditis $(1,2)$. Also, the presence of E. faecalis and $E$. faecium among dogs has been reported previously $(3,4,5)$.

Among the enterococci, Enterococcus faecalis and $E$. faecium are the most common species isolated from clinical cases, and E. durans, E. gallinarum, E. avium, E. casseliflavus, E. raffinosus, E. solitarius and $E$. hirae are less common $(3,6)$.

Corresponding author: Dr. Sukru Kirkan, $\mathrm{PhD}$

E-mail address: skirkan@adu.edu.tr

Present address: Department of Microbiology, Faculty of Veterinary

Medicine, Aydin Adnan Menderes University, Aydin, Turkey

Phone: 00902562470700

Copyright: (C) 2018 Kirkan S. This is an open-access article published under the terms of the Creative Commons Attribution License which

permits unrestricted use, distribution, and reproduction in any medium, provided the original author and source are credited.

Competing Interests: The authors have declared that no competing interests exist.

Available Online First: 3 November 2018

Published on: 15 March 2019

https://doi.org/10.2478/macvetrev-2018-0026
Enterococci have gained resistance against some antibiotics. Antibiotic resistance in enterococci may be natural or acquired. Most enterococci naturally show resistance to antimicrobials such as $\beta$-lactams, clindamycin, aminoglycosides and fluoroquinolones. Enterococci are naturally susceptible to ampicillin and vancomycin, but they may develop resistance if exposed to antibiotics excessively. Similarly, enterococci can also develop resistance to macrolides, glycopeptides (vancomycin, teicoplanin), chloramphenicol, aminoglycosides and $\beta$-lactams (7).

Another type of acquired resistance that is very important in enterococci is glycopeptide resistance, which is expressed by different phenotypes that can vary from vanA to vanG. The phenotypic classification is based on whether the bacterium is resistant to vancomycin solely or vancomycin and teicoplanin as double resistance, whether or not the resistance is inducible or structurally transmissible to other bacteria. Among the glycopeptide resistance types mentioned, the best-defined resistance are van $A, \operatorname{van} B, \operatorname{van} C$ and $\operatorname{van} D(8)$.

Enterococcus species can be transmitted through contamination of saliva, urine or faeces by direct contact from pets to humans. This transmission plays an important role in the distribution of resistant 
genes among bacterial species (9). The widespread use of antibiotics in pets has been reported to be an important reason for acquiring resistance to enterococcal species. There are different studies on the presence of enterococci in healthy dogs (nasal, rectal, oral) and antibiotic susceptibility (10). In humans, E. faecalis and E. faecium were identified and antibiotic susceptibilities of the isolates were determined by the disc diffusion method and vancomycin resistance was revealed (11).

The scope of this study was to determine the antimicrobial susceptibilities of vancomycinresistant E. faecium strains isolated from urine specimens of dogs.

\section{MATERIAL AND METHODS}

One hundred urine samples $(10 \mathrm{ml})$ were collected from 72 sick dogs (suspected of having a urinary tract infection) and 28 healthy dogs (with no clinical sign) by means of cystocentesis, which were brought to the to the Adnan Menderes University, Veterinary Faculty Research and Practice Hospital for examination. The samples were immediately taken to the Routine Diagnosis Laboratory of the Department of Microbiology of the Faculty of Veterinary Medicine of the University of Menderes in an insulated box containing ice cubes. Adnan Menderes University Animal Experiments Local Ethics Committee (ADU-HADYEK) report dated 14.08.2015 and numbered 64583101/2015/103 did not show any penalty in conducting the research.

\section{Isolation and identification of Enterococci}

The undiluted urine samples were cultured on $5 \%$ sheep blood agar and incubated at $37^{\circ} \mathrm{C}$ for 24 hours under aerobic atmosphere. At the end of this period, Gram staining method and catalase test were applied to the colonies. Catalase-negative colonies were regarded as Streptococcus sp. and inoculated into a bile esculin agar (Enterococcocel agar) for identification of enterococci. The petri dishes were incubated at $37^{\circ} \mathrm{C}$ for 24 hours under aerobic atmosphere. After that, black colonies were selected and inoculated into a brain heart infusion agar. Enterococcus sp. isolates were tested for oxidase test, PYR test, $6.5 \% \mathrm{NaCl}$ salt tolerance test and identified by genus level. The identified colonies were inoculated to broth medium for identification and stored at $-20^{\circ} \mathrm{C}$ for PCR tests.

\section{DNA isolation}

DNA isolations of strains were conducted via Genomic DNA purification kit (Fermentas $\left.{ }^{\circledR}\right)$ appropriate to procedure. The extracted DNA has been kept in cryo tubes in deep freeze at $-20^{\circ} \mathrm{C}$.

\section{Primers}

The primers used for the detection of E. faecium-E. faecalis and the presence of the vancomycine resistance genes are shown in Table 1.

\section{Positive control}

E. faecalis ATCC 29212 and E. faecium ATCC 19434 strains were used as positive control.

Table 1. Oligonucleotide primer pairs, amplicon size and target genes

\begin{tabular}{|c|c|c|c|}
\hline Primer & Target gene & Primer sequences (5'-3') & Amplicon size (bp) \\
\hline Enterococcus sp. & tuf & $\begin{array}{l}\text { TACTGACAAACCATTCATGATG } \\
\text { AACTTCGTCACCAACGCGAAC }\end{array}$ & 112 \\
\hline E. faecium & $d d l_{\text {Efaecium }}$ & $\begin{array}{l}\text { F: TAGAGACATTGAATATGCC } \\
\text { R: TCGAATGTGCTACAATC }\end{array}$ & 550 \\
\hline E. faecalis & $d d l_{\text {Effaecalis }}$ & $\begin{array}{l}\text { F: ATCAAGTACAGTTAGTCT } \\
\text { R: ACGATTCAAAGCTAACTG }\end{array}$ & 941 \\
\hline $\begin{array}{l}\text { Vancomycin } \\
\text { resistance }\end{array}$ & vanA & $\begin{array}{l}\text { F: GGGAAAACGACAATTGC } \\
\text { R: GTACAATGCGGCCGTTA }\end{array}$ & 732 \\
\hline $\begin{array}{l}\text { Vancomycin } \\
\text { resistance }\end{array}$ & $\operatorname{van} B$ & $\begin{array}{l}\text { F: ACCTACCCTGTCTTTGTGAA } \\
\text { R: AATGTCTGCTGGAACGATA }\end{array}$ & 300 \\
\hline
\end{tabular}




\section{PCR}

Identification of Enterococcus sp. was performed by a PCR assay to detect the tuf gene, with primer pairs previously described (12). Identification of $E$. faecalis and E. faecium was carried out by a PCR assay to detect $\mathrm{ddl}_{E \text {. faecalis }}$ and $\mathrm{ddl}_{E \text {. faecium }}$, respectively, with primer pairs previously described (13). Vancomycine resistance genes (van $A$ and van $C$ ) were detected by a multiplex PCR assay as described elsewhere (14).

\section{Detection of the amplification product}

The $10 \mu \mathrm{l}$ amplified products were detected by staining with $0.5 \mu \mathrm{g} / \mathrm{ml}$ ethidium bromide after electrophoresis at 80 Volt for $40 \mathrm{~min}$ in $2 \%$ agarose gel. The expected base pair size of Enterococcus sp., E. faecalis and E. faecium were 112 bp, 941 bp and 550 bp respectively. For detection of the broad vancomycine resistance genes, $732 \mathrm{bp}$ for $v a n A, 300 \mathrm{bp}$ for $v a n B$ amplicon sizes were examined.

\section{Antibiotic susceptibility}

The E-Test method was used to determine the antibiotic susceptibility of the isolated E. faecium. Tetracycline, tigecycline, clindamycin, ceftriaxone and ampicillin E-test strips supplied by Oxoid $®$ were used for the antibiogram. The MIC values obtained for the antibiotics were evaluated in accordance with the recommendation of CLSI (15).

\section{RESULTS}

Twenty-two Enterococcus sp. isolates were identified by PCR as E. faecium (Table 2; Fig. 2). The electrophoresis image of the isolates is shown in Fig. 1.

Table 2. Identification rates of Enterococcus sp.

\begin{tabular}{ccc}
\hline Isolate (n) & $\begin{array}{c}\text { Identification } \\
\text { number }\end{array}$ & $\begin{array}{c}\text { Identification } \\
\text { rate }\end{array}$ \\
\hline E. faecalis & - & - \\
\hline E. faecium & 22 & 100 \\
\hline
\end{tabular}

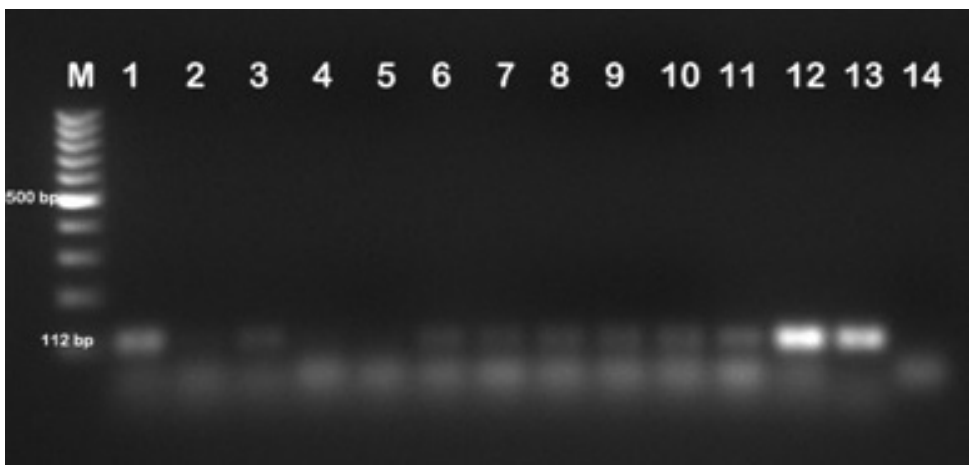

Figure 1. Enterococcus sp. electrophoresis gel image M:100 bp DNA ladder, 1-11: Enterococcus sp. positive samples, 12: E. faecalis ATCC 29212 positive control, 13: E. faecium ATCC 19434 positive control, 14: Negative control

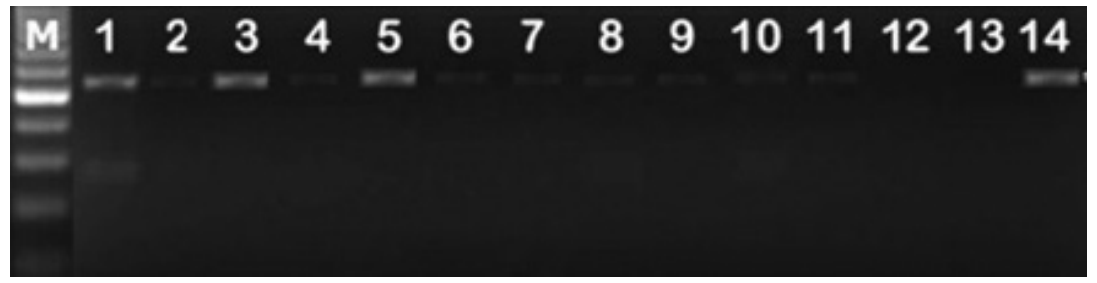

Figure 2. E. faecium electrophoresis gel image M:100 bp DNA ladder, 1-11: E. faecium positive samples, 12: E. faecalis ATCC 29212 positive control, 13: Negative control, 14: E. faecium ATCC 19434 positive control 


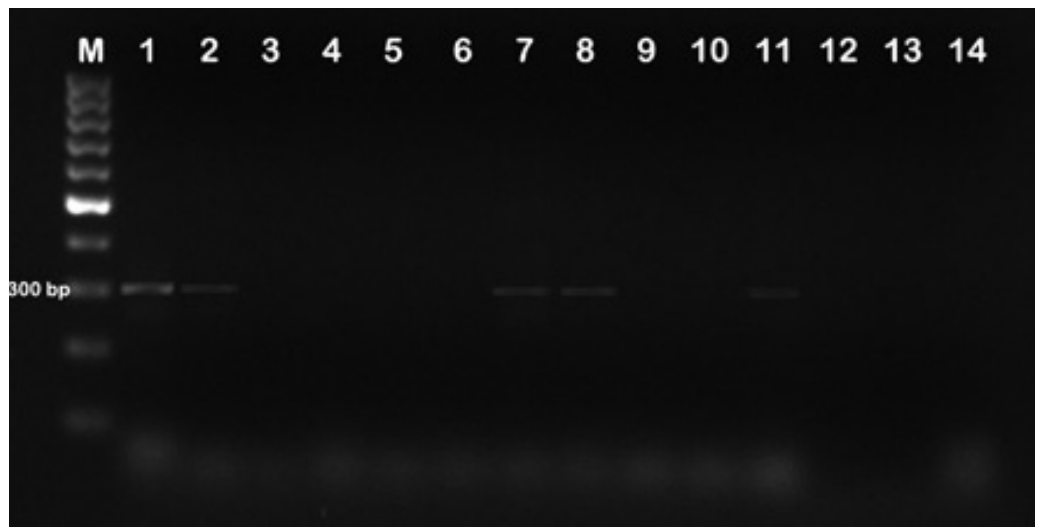

Figure 3. Vancomycin resistance electrophoresis gel image M:100 bp DNA ladder, 1-2-7-8-11: vanB positive samples, 3-4-5-6-9-10-12: vanB negative samples 12: E. faecalis ATCC 29212 positive control, 13: E. faecium ATCC 19434 positive control, 14: Negative control

Table 3. MIC of E. faecium isolates

\begin{tabular}{ccccc}
\hline Antimicrobial agent & MIC Range $(\mu \mathrm{g} / \mathrm{ml})$ & MIC $50(\mu \mathrm{g} / \mathrm{ml})$ & MIC $90(\mu \mathrm{g} / \mathrm{ml})$ & Resistance $(\%)$ \\
\hline Ampicillin & $4-0.12$ & 0.5 & 1 & 100 \\
Tetracycline & $128-2$ & 16 & 128 & 100 \\
Tigecycline & $16-0.12$ & 2 & 4 & 100 \\
Clindamycin & $32-0.06$ & 16 & 32 & 100 \\
Ceftriaxone & $128-2$ & 128 & 128 & 100 \\
\hline
\end{tabular}

Ten (45\%) E. faecium isolates had vancomycin resistance to the vanB gene (Fig. 3). The Enterococcus sp. were isolated from clinically sick animals. The other bacterial isolates identified from this study were Bacillus sp. $(\mathrm{n}=17)$, Streptococcus sp. $(\mathrm{n}=18)$, Staphylococcus $\mathrm{sp} .(\mathrm{n}=13)$ and Klebsiella sp. $(n=12)$.

All of the $22 \mathrm{E}$. faecium isolates were found to be $100 \%$ resistant to tigecycline, ampicillin, tetracycline, clindamycin and ceftriaxone. The antimicrobial resistance results of E. faecium isolates are shown in Table 3.

\section{DISCUSSION}

Antimicrobial resistance is a noteworthy concern in animal health throughout the world. Indeed, the enterococci are known to be ubiquitous microorganisms found in various habitats of animals. They recently emerged as a significant agent of multiple drug resistance infections $(16,17)$. In dogs, enterococci are known to be both bacterial flora elements and infections (18).
The present study investigated the urogenital carriage of enterococci among pet dogs, with reference to antimicrobial resistance. The evaluation of urine culture of dogs with UTIs revealed that $E$. faecium was the only identified enterococcal species from dogs in this study. Similarly, E. faecium was reported to be most common species isolated from dogs in previous studies carried out in Turkey (19, 20). However in another study, E. faecalis has been identified to be predominantly isolated from urinary tract infections of dogs as a causative agent (21). The results of the current study showed greater isolation rates of E. faecium in the urine samples of dogs $(22 \%)$ compared with E. faecalis $(0 \%)$. Such results agree with the findings of Rodrigues et al. (3) but contradict the results of Jackson et al. who found that $E$. faecalis was the predominant species among the examined dogs (22).

Furthermore, in a study conducted with molecular typing methods, a high degree of diversity was observed between similar and related strains isolated from human and animal specimen. It has been reported that the transposon Tn1546, which is found in human enterococcal isolates, is also shown 
in the urine-infected enterococcus species of dogs, and can be a proof of gene mutation between human and animal-bearing species resistant to vancomycin $(19,23)$.

A large proportion of enterococcus strains are naturally resistant to antimicrobial agents used in the treatment of Gram-positive bacterial infections (24). Numerous antibiotics such as penicillins, cephalosporins, quinolones and low levels of aminoglycosides have been shown to exhibit natural resistance, as well as that enterococci can produce antibiotic resistance through new mechanisms and transfer through these resistance plasmids (25). In our study, we found that all strains were resistant to tigecycline, ampicillin, tetracycline, clindamycin and ceftriaxone, and this should be considered when suggesting amtimicrobial therapy options for urinary tract infections in dogs.

Although vancomycin has been reported to be the most effective antibiotic against enterococci, the increase in the number of vancomycin-resistant strains has been reported as significant. There are multiple vancomycin resistant phenotypes, including van $A, v a n B, v a n C$, vanD, vanE, and vanG. The most clinically important strains are van $A$ and van $B$ resistant strains. Strains with the van $A$ gene show the highest resistance to vancomycin and teicoplanin, while strains with the vanB gene show only resistance to vancomycin (24).

In this study, vanB resistance was detected in 10 $(45 \%)$ E. faecium isolates. As a result of the E-test, E. faecium isolates were $100 \%$ resistant against tigecycline, ampicillin, tetracycline, clindamycin and ceftriaxone. The impact of the results indicates an emergency for pet owners, since the antimicrobial resistant $E$. faecium strains may infect people living with dogs.

\section{CONCLUSION}

Multiple drug resistant E. faecium was isolated and identified from dogs with UTIs in this study. The identification of E. faecium from dogs with UTIs supports the claim of enterococci being a true uropathogen rather than solely an opportunistic organism. Besides, the gross resistance to multiple antimicrobials strongly indicated that treatment of UTIs should not be initialised before the results of urine culture and antibacterial susceptibility are reported, especially because random applications can result in overgrowth of non-susceptible bacteria. However, when random use of antibiotics is inevitable, reasonable use is necessary to reduce or exclude the increase of antimicrobialresistant organisms and to maintain the efficacy of antimicrobials in veterinary medicine. Hence, antimicrobial susceptibility monitoring programmes are essential tools for developing appropriate therapy protocols for urinary tract infections of dogs.

\section{CONFLICT OF INTEREST STATEMENT}

The authors declared that they have no potential conflict of interest with respect to the authorship and/or publication of this article.

\section{ACKNOWLEDGMENT}

This research was funded by Aydin Adnan Menderes University Scientific Research Committee (Project code: VTF-15067).

\section{REFERENCES}

1. Kwon, K.H., Moon, B.Y., Hwang, S.Y., Park, Y.H. (2012). Detection of CC17 Enterococcus faecium in dogs and a comparison with human isolates. Zoonoses Public Health 59, 375-378. https://doi.org/10.1111/j.1863-2378.2012.01466.x PMid:22372965

2. Wong, C., Epstein, S.E., Westropp, J.L. (2015). Antimicrobial susceptibility patterns in urinary tract infections in dogs (2010-2013). J Vet Inter Med. 29, 1045-1052.

https://doi.org/10.1111/jvim.13571

PMid:26133165 PMCid:PMC4895361

3. Rodrigues, J., Poeta, P., Martins, A., Costa, D. (2002). The importance of pets as reservoirs of resistant Enterococcus strains, with special reference to vancomycin. J Vet Med B. 49 (6): 278-280. https://doi.org/10.1046/j.1439-0450.2002.00561.x PMid:12241027

4. Damborg, P., Sorensen, A.H., Guardabassi, L. (2008). Monitoring of antimicrobial resistance in healthy dogs: first report of canine ampicillinresistant Enterococcus faecium clonal complex 17. Vet Microbiol. 132, 190-196.

https://doi.org/10.1016/j.vetmic.2008.04.026 PMid:18524501

5. Jackson, C.R., Fedorka-Cary, P.J., Davis, J.A., Barrett, J.B., Frye, J.G. (2009). Prevalence, species distribution and antimicrobial resistance of enterococci isolated from dogs and cats in the United States. J Appl Microbiol. 107, 1269-1278. https://doi.org/10.1111/j.1365-2672.2009.04310.x PMid:19486402 
6. Schouten, M.A., Vose, A., Hoogkamp-Karstanje, J.A.A. (1999). Antimicrobial susceptibility patterns of enteroccocci causing infections in Europe. Antimicrob Agents Chemother. 43, 2542-2546.

https://doi.org/10.1128/AAC.43.10.2542

PMid:10508041 PMCid:PMC89517

7. Marothi, Y.A., Agrihotri, H., Dubey, D. (2005). Enterococcal resistance-An overview. Indian J Med Microbiol. 23, 214-219.

PMid:16327115

8. Klare, I., Konstabel, C., Badstubner, D., Werner, G., Witte, W. (2003). Occurrence and spread of antibiotic resistances in Enterococcus faecium. Int J Food Microbiol. 88, 269-290. https://doi.org/10.1016/S0168-1605(03)00190-9

9. Franz, C.M.A.P., Stiles, M.E., Schleifer, K.H., Holzapfel, W.H. (2003). Enterococci in foods - a conundrum for food safety. Int J Food Microbiol. 88, 105-122.

https://doi.org/10.1016/S0168-1605(03)00174-0

10. Jackson, C.R., Fedorka-Cray, P.J., Barrett, J.B. (2004). Use of a genus- and species-specific multiplex PCR for identification of Enterococci. J Clin Microbiol. 42 (8): 3558-3565.

https://doi.org/10.1128/JCM.42.8.3558-3565.2004

PMid:15297497 PMCid:PMC497640

11. Shankar, N., Baghdayan, A.S., Gilmore, M.S. (2002). Modulation of virulence within a pathogenicity island in vancomycin resistant Enterococcus faecalis. Nature 417, 746-750.

https://doi.org/10.1038/nature00802

PMid:12066186

12. Ke, D., Picard, F.J., Martineau, F., Menard, C., Roy, P.H., Ouellette, M., Bergeron, M.G. (1999). Development of a PCR assay for rapid detection of enterococci. J Clin Microbiol. 37, 3497-3503. PMid:10523541 PMCid:PMC85677

13. Dutka-Malen, S., Evers, S., Courvalin, P. (1995). Detection of glycopeptide resistance genotypes and identification to the species level of clinically relevant enterococci by PCR. J Clin Microbiol. 33, 24-27.

PMid:7699051 PMCid:PMC227872

14. d'Azevedo, P.A., de Souza Santiago, K.A., Furtado, G.H.C., Xavier. D.B., Pignatari, A.C.C., de-Almeida, R.T. (2009). Rapid detection of vancomycin-resistant enterococci (VRE) in rectal samples from patients admitted to intensive care units. Braz J Inf Dis. 13 (4): 289-293.

https://doi.org/10.1590/S1413-86702009000400010 PMid:20231993
15. Clinical and laboratory standards institute (CLSI) performans standards for antimicrobial ausceptability testing; 27th Informational Supplement 2017, M100-S26.

16. Lebreton, F., Willems, R.J.L., Gilmore, M.S. [Internet]. Enterococcus diversity, origins in nature, and gut colonization. In: Gilmore MS, Clewell DB, Ike Y, Shankar N (Ed.), Enterococci: from commensals to leading causes of drug resistant 1nfection. Boston: Massachusetts Eye and Ear Infirmary [cited 2018 June 01].

https://www.ncbi.nlm.nih.gov/pubmed/24649513

17. Agudelo Higuita, N.I., Huycke, M.M. [Internet]. Enterococcal disease, epidemiology, and 1mplications for treatment. In: Gilmore MS, Clewell DB, IkeY, Shankar N (Ed.), Enterococci: from commensals to leading causes of drug resistant infection [cited 2018 June 01].

https://www.ncbi.nlm.nih.gov/pubmed/24649513

18. Cinquepalmi, V., Monno, R., Fumarola, L., Ventrella, G., Calia, C., Greco, M.F., Vito, D., Soleo, L. (2013). Enviromental contamination by dog's faeces : a public health problem ? Int J Environ Res Public Health 10 (1): 72-84. https://doi.org/10.3390/ijerph10010072 PMid:23263659 PMCid:PMC3564131

19. Turkyılmaz, S., Erdem, V., Bozdoğan, B. (2010). Investigation of antimicrobial susceptibility for enterococci isolated from cats and dogs and the determination of resistance genes by polymerase chain reaction. Turk Vet J Anim Sci. 34, 61-68.

20. Boynukara, B., Ekin, İ.H., Aksakal, A., Gulhan, T. (2002). Isolation and antibiotic susceptibility of enterococci from human, dog and cat faeces. Vet Hek Mikrobiyol Derg. 2 (1): 37-42.

21. KuKanich, K.S., Lubbers, B.V. (2015). Review of enterococci isolated from canine and feline urine specimens from 2006 to 2011. J Am Anim Hosp Assoc. 51, 148-154.

https://doi.org/10.5326/JAAHA-MS-6070

PMid:25955138

22. Jackson, C.R., Fedorka-Cary, P.J., Davis, J.A., Barrett, J.B., Frye, J.G. (2009). Prevalence, species distribution and antimicrobial resistance of enterococci isolated from dogs and cats in the United States. J Appl Microbiol. 107, 1269-1278. https://doi.org/10.1111/j.1365-2672.2009.04310.x PMid:19486402 
23. Ghosh, A., Dowd, S.E., Zurek, L. (2011). Dogs leaving the ICU carry a very large multi-drug resistant enterococcal population with capacity for biofilm formation and horizontal gene transfer. PLoS ONE 6:e22451.

https://doi.org/10.1371/journal.pone.0022451

PMid:21811613 PMCid:PMC3139645

24. Güçkan, R., Elmas, A., Tilgel, S., Yüksel, G. (2013). Antibiotic susceptibility of Enterococci strains isolated from various clinical samples. Int $\mathrm{J}$ Basic Clin Med. 1, 74-77. [in Turkish]
25. Moellering J.C. (2000). Enterococcus species. In: G.L. Mandell (Ed.), Principles and practise of infectious diseases (pp. 2147-2156). NewYork: Churcill Livingstone. 